\title{
Central adiposity in Brazilian schoolchildren aged 7-10 years
}

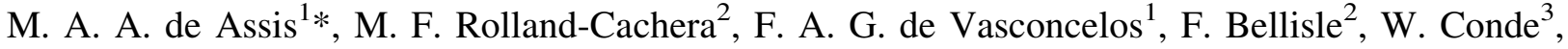 \\ M. C. M. Calvo ${ }^{4}$, M. E. P. Luna ${ }^{5}$, M. J. Ireton ${ }^{6}$ and S. Grosseman ${ }^{7}$ \\ ${ }^{1}$ Department of Nutrition, Santa Catarina Federal University, Avenida Rubens de Arruda Ramos 1808/1201, Florianópolis \\ 88015-700, Santa Catarina, Brazil \\ ${ }^{2}$ UMR U 557 INSERM/U 1125 INRA/CNAM/Paris 13, CRNH Ile de France, Paris, France \\ ${ }^{3}$ Department of Nutrition, Faculdade de Saude Publica, São Paulo University, Sao Paulo, SP, Brazil \\ ${ }^{4}$ Department of Public Health, Santa Catarina Federal University, Florianópolis, SC, Brazil \\ ${ }^{5}$ Health Secretary, Prefeitura Municipal de Florianópolis, Florianópolis, SC, Brazil \\ ${ }^{6}$ Unidad de Auxiología, Facultat de Medicina, Universidad Nacional de Colômbia, Bogotá, Colombia \\ ${ }^{7}$ Department of Paediatrics, Santa Catarina Federal University, Florianópolis, SC, Brazil
}

(Received 24 April 2006 - Revised 24 October 2006 - Accepted 25 October 2006)

\begin{abstract}
Waist circumference (WC) is a measure of central adiposity related to elevated risk factor levels in children and adolescents. The aim of the present study was to describe WC percentiles in 7- to 10-year-old Brazilian children and to compare frequencies of obesity and overweight as defined by BMI and frequencies of excess and at risk of abdominal adiposity as defined by WC to the corresponding age and sex data from British references. A representative sample of 2919 schoolchildren of the city of Florianopolis (southern Brazil) was examined. Smoothed WC percentiles were derived using the least mean square method. Frequencies of overweight and obesity and of excess and at risk of abdominal adiposity were assessed using the 91st and 98th centiles of the British references as cut-off points. WC increased with age in both boys and girls, with higher values for boys at every age and percentile level. Nutritional status categories of children assessed by the 91st and 98th British BMI and WC centiles showed moderate agreement (weighted $\kappa=0.58$ ). Overweight was more frequent in Brazilian than British children: $15 \cdot 1 \%$ of girls and $20 \cdot 1 \%$ of boys were above the 91st percentile of the 1990 BMI for age British references. About one-quarter (22.0\% of girls and $26.9 \%$ of boys) exceeded the 91st percentile of WC British references. The present data could be used to compare WC in children in other populations and may serve as a baseline for future studies of temporal trends in WC in Brazil.
\end{abstract}

Central adiposity: Waist circumference percentiles: Childhood: Obesity prevalence: Brazil

Recent studies have shown that waist circumference (WC) increased much faster than BMI in children and adolescents over the past 10-20 years (McCarthy et al. 2003, 2005; Moreno et al. 2005).

While the BMI is generally accepted and used to classify children as overweight or obese in population studies, it is recognised that the BMI cannot distinguish between muscle and fat masses and gives no indication about body adiposity distribution (Reilly et al. 2000). The BMI therefore seems a poor proxy for central adiposity. The WC is a highly sensitive and specific measure of trunk adiposity (Taylor et al. 2000) and a strong predictor of visceral adiposity in the paediatric population (Brambilla et al. 2006; Lee et al. 2006). Further, WC is related to metabolic complications of obesity, including poor lipid profile, increased blood pressure and insulin resistance in children and adolescents (Freedman et al. 1999; Savva et al. 2000; Maffeis et al. 2001; Moreno et al. 2002).
It has therefore been recommended that WC should be used to identify young individuals at risk of morbidity associated with central body adiposity and could be adopted as an alternative or additional measurement to BMI (McCarthy et al. 2003). However, there are no commonly accepted WC cut-offs for classifying children with high central adiposity.

The prevalence of overweight based on BMI has tripled in Brazilian children and adolescents over the past two decades (Wang et al. 2002); however, there are no data on WC values and the level of central adiposity in Brazilian children and adolescents.

The aim of the present study was to: (a) describe WC centiles in 7- to 10-year-old Brazilian children derived from 2919 schoolchildren living in Florianopolis; (b) describe the prevalence of overweight and obesity as defined by BMI and the prevalence of at-risk abdominal adiposity and excess abdominal adiposity as defined by WC, using British reference data in

\footnotetext{
Abbreviations: LMS, least mean square; SES, socio-economic status; STR, subscapular:triceps skinfold ratio; WC, waist circumference; WHtR, waist:height ratio. * Corresponding author: Dr M. A. A. de Assis, fax 55 (48) 333195 42, email massis@ccs.ufsc.br
} 
the same population; (c) examine the agreement between two measures of adiposity, based on BMI and WC.

These data are important to allow valuable comparisons with other studies and to monitor the prevalence of (central) adiposity over time.

\section{Methods}

\section{Subjects}

The present study was conducted in the city of Florianopolis, from September to November 2002. Florianopolis is the capital of the province of Santa Catarina, in the south of Brazil.

The study design has been described elsewhere (de Assis et al. 2005). Briefly, a representative sample of 7- to 10year-old schoolchildren attending the first four grades of elementary schools of the city was selected, using a stratified multistage cluster-sampling design. Information included anthropometric data (height, weight, skinfolds and circumferences) and socio-economic status (SES) of the family. Parents completed a questionnaire with sociodemographic information, including monthly family income. Tertiles of monthly family income were used to indicate low, medium and high SES.

Of the 3313 eligible children, 377 had missing anthropometric data (child absent or ill; child refused to participate). In the present article 2926 children ( 1502 boys and 1424 girls), with complete information on age, sex, school level, SES and all anthropometric measurements were included (88.3\%). Participation rate did not significantly differ according to sex and age. However, SES differed between participants and non-participants: more participants were categorised in the low and medium SES and fewer in the high SES compared with non-participants (low SES, 48.8 v. 38.6\%; medium SES, 21.7 v. 14.6\%; high SES, 29.5 v. $46.7 \% ; P<0.01)$.

Santa Catarina's population is predominantly of European origin; specific information on ethnicity was not available in the present study.

Parents gave written informed consent to their child's participation in the study, which received approval from the Committee on Human Studies of the Federal University of Santa Catarina.

\section{Anthropometric measurements}

The administrative department of each school provided information on age, based on birth certificates. Anthropometric measurements of participants were taken by trained technicians, according to the procedures recommended by Lohman et al. (1988).

Anthropometric measurements were performed in lightly dressed children, without shoes. Weight was measured with a digital-solar $180 \mathrm{~kg}$ scale (Marte ${ }^{\circledR}$ model PP; Marte Scale and Precision Equipment, Minas Gerais, Brazil). Height was measured using a metric tape fixed to a wall without a baseboard, with the child standing up, weight being equally distributed on both feet, with the head held in the Frankfort plane and head back and buttocks on the vertical land on the height gauge. The triceps and subscapular skinfold thicknesses were measured to the nearest $\mathrm{mm}$ with a skinfold caliper (Cescorf $^{\circledR}$; Scientific Sports Equipment, Porto Alegre, RGS,
Brazil). Triceps skinfold was measured at the midpoint between the acromion and olecranon process. Subscapular skinfold was measured about $20 \mathrm{~mm}$ below the tip of the scapula, at a $45^{\circ}$ angle to the lateral side of the body. The mean of triplicate records was used in the analysis. The WC was measured to the nearest $\mathrm{mm}$ with a flexible non-elastic tape, midway between the tenth rib and the iliac crest. The BMI was computed as weight in $\mathrm{kg}$ divided by height in $\mathrm{m}^{2}$. Two other indicators of central adiposity were also examined: the waist:height ratio (WHtR) as an index of abdominal adiposity; the subscapular:triceps skinfold ratio (STR) as an index of trunk adiposity.

\section{Data analysis}

The data were first examined for outliers, and those with WC values exceeding \pm 5 age-standardised SD scores were eliminated (six girls and one boy). The final analytical population contained 2919 children (1501 boys and 1418 girls).

Weight, height, WC, BMI, WHtR and STR are presented as medians and ranges by sex and age. Because anthropometric variables were not normally distributed (Kolmogorov-Smirnov test), non-parametric tests were used. Differences between sexes in each age group were assessed using the Mann-Whitney $U$ test. Differences across ages for each sex were assessed using the Kruskal-Wallis $H$ test. Regression analysis with the Pearson coefficient was used to examine the relationship of WC and WhTR to height in each age group and sex. The association was controlled by age as a continuous variable to take into account even small differences.

Smoothed percentiles for WC were constructed from the raw data using the 'COLELMS' command in STATA ${ }^{\circledR}$ to calculate the crude least mean square (LMS) values. The LMS method enables normalised growth centile standards to be developed, and deals with skewness which might be present in the distribution of the measurements. The LMS method summarises the changing distributions by three independent curves representing the median, $\mathrm{CV}$ and skewness, the latter expressed as a Box-Cox power (Cole, 1990). The 50th and the 90th centiles values of WC were compared with data from the UK (McCarthy et al. 2001) and with data from the USA for American-European children (Fernández et al. 2004).

Overweight and obesity were estimated using cut-off points corresponding to the 91st and 98th centiles (SD scores of 1.33 and 2, respectively) of the British reference populations based on BMI (Cole et al. 1995); at risk of abdominal adiposity and excess of abdominal adiposity were estimated using cut-off points corresponding to the 91st and 98th centiles of the WC British reference, respectively (McCarthy et al. 2001). Similar cut-off points allow prevalence of at risk and excess abdominal adiposity (defined by WC) to be compared with that of overweight or obesity (defined by BMI), using the British reference populations, as described by McCarthy et al. (2003). The 91st and 98th centiles for BMI are similar to the cut-off points based on adult BMI health-risk-related outcomes for overweight and obesity defined by the International Obesity Task Force (Cole et al. 2000).

Overall frequencies of total overweight or obesity and at risk or excess of abdominal adiposity were computed by using direct standardisation on age and sex. Comparisons of frequencies between sexes were performed using the $\chi^{2}$ test. 
The agreement between the two measures of adiposity was analysed by the weighted $\kappa$ statistic. Discordant subgroups of children classified as non-overweight according to the BMI cut-off, but as at risk and with an excess of abdominal adiposity according to the WC cut-off (WC-only group), were compared with those classified as without abdominal adiposity according to the WC cut-off, but overweight and obese according to the BMI cut-off (BMI-only group), for the ancillary anthropometric variables: height, WHtR and STR.

The significance level was set at $P<0 \cdot 05$. Statistical analyses were performed with SPSS version 10.0 and STATA ${ }^{\circledR}$ version 8.0 (Statistical Analysis System software, version 8.0, 1989; SAS Institute, Cary, NC, USA).

\section{Results}

Table 1 presents medians and ranges for anthropometric characteristics by age and sex. Weight, height, BMI, WC and STR increased with age in both boys and girls, while WHtR decreased with age in both sexes. Boys tended to have higher values for BMI than girls; however, significant sex differences occurred only at age 8 years. Between sexes, boys presented higher WC $(P<0.001)$ and WHtR $(P$ ranging between 0.01 and 0.001) than girls in all age groups.

WC was moderately correlated with height in all age groups, for both sexes $(P<0.001)$. In the analysis of the entire sample, the Pearson correlation coefficients between WC and height, after controlling for age, were $r 0.57$ $(P<0.001)$ for boys and $r 0.54(P<0.001)$ for girls. In contrast, a weaker correlation was seen between WHtR and height, for both boys $(r 0.11 ; P<0.04)$ and girls $(r 0.16$; $P<0 \cdot 3$ ).

Table 2 presents the smoothed sex- and age-specific WC values at the 5 th, 10th, 15th, 25th, 50th, 75th, 85th, 90th and 95th percentiles. Boys had higher values than girls at every age and percentile point. The difference between boys and girls on the 95th percentile at age 10 years was $4.4 \mathrm{~cm}$.

Fig. 1 compares the WC data of Florianopolis school children with the British (McCarthy et al. 2001) and US (Fernández et al. 2004) reference populations. Compared with the British reference, Florianopolis children had higher levels of WC at the 50th and 90th percentiles, in the same age range. At the 90th percentile differences increased substantially, ranging from 6.1 to $8.7 \mathrm{~cm}$ for boys and from 5.3 to $7.5 \mathrm{~cm}$ for girls. Compared with the US data, Florianopolis children had slightly lower 50th percentile WC values, but the difference was much larger between 90th percentiles. At the 90th percentile, differences between Florianopolis and US children ranged from 1.8 to $3.7 \mathrm{~cm}$ for boys and from 2.8 to $5.0 \mathrm{~cm}$ for girls.

Age-standardised frequencies of obesity and overweight (non-obese), using the BMI cut-offs (Cole et al. 1995) and excess abdominal adiposity and at-risk abdominal adiposity, using the WC cut-offs (McCarthy et al. 2001), estimated in boys and girls separately, are presented in Table 3. Using British reference values, $5.6 \%$ of girls and $8.3 \%$ of boys were above the 98th percentile for BMI-for-age, and $15.1 \%$ of girls and $20.1 \%$ of boys were above the 91 st percentile. The corresponding values for WC were $10.1 \%$ of girls and $13.4 \%$ of boys exceeding the 98th percentile and $22.0 \%$ of girls and $26.9 \%$ of boys exceeding the 91 st percentile of British WC references. In all age groups total and centrally distributed adiposity prevalences were significantly higher than expected on the basis of British reference data $(P<0 \cdot 001)$, except for BMI-overweight and obesity prevalence in 10-year-old girls.

Between sexes, a difference was observed in frequency of overweight (non-obese) according to the BMI British reference in 10-year-old children $(13.5 \%$ for boys v. $5.9 \%$ for girls; $P=0 \cdot 001)$. Frequencies of obesity (BMI) did not differ significantly between boys and girls, whatever the age group. Using British WC references, 8- and 9-year-old boys presented higher frequencies of excess abdominal adiposity compared with girls in the same age groups $(P=0 \cdot 003)$.

Nutritional status categories of children assessed by BMI (non-overweight, overweight and obese) and assessed by WC (without abdominal adiposity, at risk of abdominal adiposity and excess of abdominal adiposity) showed $84.9 \%$ agreement. When analysis was stratified by sex, the agreement was slightly higher for girls compared with boys $(86 \cdot 2 v$. $83.6 \% ; P=0.046)$. The amount of agreement beyond that explained by chance as described by the $\kappa$ statistic showed a moderate agreement for both boys $(\kappa 0.58)$ and girls ( $\kappa$ 0.57). Table 4 presents mean values and standard deviations for the ancillary anthropometric variables in subgroups of children only detected by the WC cut-off for abdominal fat (WConly group) and the group only detected by the BMI cut-off for overweight and obesity (BMI-only group). Overall, 252 of the 2403 children (10.5\%) were classified as non-overweight according to BMI but at risk of abdominal adiposity according to WC cut-offs. By contrast, the BMI cut-off identified fifty-two children (2.4\% of 2203) as overweight or obese, which were not identified as at risk of abdominal adiposity by the WC cut-off. In subgroups of children where BMI and WC percentiles were discordant, an elevated WC preferentially identified children who were taller and also had higher WHtR. There was no mean age difference between children detected by the WC-only group and children detected by the BMI-only group $(9 \cdot 2(\mathrm{SD} 1 \cdot 1)$ v. $9 \cdot 0(\mathrm{SD} 1 \cdot 1)$ years; $P=0 \cdot 2)$.

\section{Discussion}

In the present article we compared the estimated frequencies of centrally distributed adiposity (as defined by WC) and total adiposity (as defined by BMI) in 7- to 10-year-old schoolchildren living in a city located in the south of Brazil to the corresponding age and sex data from British references. We also presented age- and sex-specific WC percentiles for these children in order to allow valuable comparisons with other populations.

Some limitations of the present study have to be considered. The data were not representative for the whole country, but to the best of our knowledge this is the most up-to-date large set of data on WC in 7- to 10-year-old Brazilian children. Santa Catarina's population is predominantly of European origin; however, specific information on ethnicity was not available in the present study. Due to a high degree of miscegenation in the Brazilian population, it might be advisable to develop standards in the national context, with representative samples of children from all ethnic backgrounds.

A difficulty in this type of research is the absence of commonly accepted cut-offs for classifying children with high WC. This is in contrast with the BMI, for which the 
Table 1. Anthropometric characteristics of 2919 schoolchildren by age and sex (Medians and ranges)

\begin{tabular}{|c|c|c|c|c|c|c|c|c|c|c|}
\hline \multirow[b]{2}{*}{ Age (years) } & \multicolumn{4}{|c|}{ Boys } & \multirow{2}{*}{$\begin{array}{l}\text { Significance } \\
\text { of difference } \\
\text { across age }\end{array}$} & \multicolumn{4}{|c|}{ Girls } & \multirow{2}{*}{$\begin{array}{l}\text { Significance } \\
\text { of difference } \\
\text { across age }\end{array}$} \\
\hline & 7 & 8 & 9 & 10 & & 7 & 8 & 9 & 10 & \\
\hline$n$ & 337 & 385 & 423 & 356 & & 323 & 384 & 373 & 338 & \\
\hline \multicolumn{11}{|l|}{ Weight (kg) } \\
\hline Median & $26 \cdot 3^{*}$ & $29 \cdot 2^{*}$ & $31 \cdot 2$ & 34.9 & $P<0.05$ & $25 \cdot 2$ & $27 \cdot 9$ & 31.7 & 34.6 & $P<0.05$ \\
\hline Range & $17 \cdot 8-47 \cdot 2$ & $17 \cdot 6-59 \cdot 0$ & $20 \cdot 2-62 \cdot 2$ & $17 \cdot 6-73 \cdot 1$ & & $17 \cdot 3-47 \cdot 4$ & $16 \cdot 8-52 \cdot 1$ & $18 \cdot 2-64 \cdot 7$ & $19 \cdot 1-73 \cdot 7$ & \\
\hline \multicolumn{11}{|l|}{ Height $(\mathrm{cm})$} \\
\hline Median & $126 \cdot 5^{\star}$ & $131 \cdot 3^{*}$ & $136 \cdot 4$ & 141.4 & $P<0.05$ & $125 \cdot 3$ & $130 \cdot 1$ & $136 \cdot 2$ & $141 \cdot 2$ & $P<0.05$ \\
\hline Range & $112 \cdot 0-152 \cdot 8$ & $112 \cdot 0-152 \cdot 0$ & $116.8-159.9$ & $113 \cdot 0-160 \cdot 0$ & & $111 \cdot 0-142 \cdot 0$ & $111.7-156.7$ & $112 \cdot 2-160 \cdot 0$ & $119 \cdot 8-160 \cdot 0$ & \\
\hline \multicolumn{11}{|l|}{$\mathrm{BMI}\left(\mathrm{kg} / \mathrm{m}^{2}\right)$} \\
\hline Median & $16 \cdot 3$ & $16 \cdot 8^{*}$ & $16 \cdot 7$ & 17.4 & $P<0.05$ & $16 \cdot 1$ & $16 \cdot 5$ & $17 \cdot 0$ & $17 \cdot 1$ & $P<0.05$ \\
\hline Range & $12 \cdot 6-25 \cdot 9$ & $13 \cdot 3-30 \cdot 0$ & $12 \cdot 6-29 \cdot 7$ & $12 \cdot 8-28 \cdot 7$ & & $13 \cdot 2-27 \cdot 5$ & $12 \cdot 6-25 \cdot 5$ & $13 \cdot 0-30 \cdot 8$ & $12 \cdot 6-31 \cdot 7$ & \\
\hline \multicolumn{11}{|l|}{ WC (cm) } \\
\hline Median & $56.0^{*}$ & $58.0^{*}$ & $59 \cdot 1^{*}$ & $60 \cdot 5^{\star}$ & $P<0.05$ & 54.5 & 55.5 & $58 \cdot 0$ & 59.0 & $P<0.05$ \\
\hline Range & $47 \cdot 5-79 \cdot 6$ & $48 \cdot 6-89.6$ & $49 \cdot 0-89 \cdot 0$ & $49.5-89.5$ & & $47 \cdot 0-78 \cdot 0$ & $47 \cdot 0-79 \cdot 0$ & $48.5-88.5$ & $48 \cdot 0-89 \cdot 0$ & \\
\hline \multicolumn{11}{|l|}{ WHtR } \\
\hline Median & $0.446^{*}$ & $0.441^{*}$ & $0.438^{*}$ & $0.431^{*}$ & $P<0.05$ & 0.439 & 0.430 & 0.428 & 0.418 & $P<0.05$ \\
\hline Range & $0.38-0.60$ & $0.38-0.67$ & $0.35-0.62$ & $0.36-0.63$ & & $0.36-0.60$ & $0.36-0.59$ & $0.34-0.59$ & $0.34-0.58$ & \\
\hline \multicolumn{11}{|l|}{ STR } \\
\hline Median & 0.56 & 0.57 & 0.59 & 0.59 & $P<0.05$ & 0.56 & 0.56 & 0.57 & 0.61 & $P<0.05$ \\
\hline Range & $0.31-6.47$ & $0.23-1.74$ & $0.26-1.99$ & $0.28-3.03$ & & $0.28-2.93$ & $0.05-1.59$ & $0.26-6.38$ & $0.28-3.88$ & \\
\hline
\end{tabular}

WC, waist circumference; WHtR, waist:height ratio; STR, subscapular:triceps skinfold ratio.

${ }^{*}$ Median value was significantly different from that of the girls in a given age group $(P<0 \cdot 05)$. 
Table 2. Values of percentiles of waist circumference $(\mathrm{cm})$ by age and sex

\begin{tabular}{|c|c|c|c|c|c|c|c|c|c|}
\hline \multirow[b]{2}{*}{ Age (years) } & \multicolumn{9}{|c|}{ Percentiles } \\
\hline & 5th & 10th & 15th & 25th & 50th & 75th & 85th & 90th & 95th \\
\hline \multicolumn{10}{|l|}{ Boys } \\
\hline 7 & 51.2 & $52 \cdot 3$ & $53 \cdot 1$ & 54.4 & $57 \cdot 3$ & $60 \cdot 8$ & 63.1 & 64.9 & 68.0 \\
\hline 8 & $52 \cdot 2$ & 53.5 & 54.4 & $56 \cdot 0$ & 59.4 & 63.8 & $66 \cdot 8$ & $69 \cdot 2$ & 73.4 \\
\hline 9 & 53.4 & 54.8 & $55 \cdot 8$ & 57.5 & $61 \cdot 2$ & $66 \cdot 0$ & $69 \cdot 3$ & 71.9 & $76 \cdot 8$ \\
\hline 10 & 54.9 & $56 \cdot 3$ & $57 \cdot 3$ & $59 \cdot 0$ & $62 \cdot 8$ & $67 \cdot 7$ & $71 \cdot 2$ & 74.0 & $79 \cdot 1$ \\
\hline \multicolumn{10}{|l|}{ Girls } \\
\hline 7 & 50.5 & 51.5 & 52.3 & 53.5 & $56 \cdot 2$ & $59 \cdot 8$ & $62 \cdot 1$ & $64 \cdot 0$ & $67 \cdot 3$ \\
\hline 8 & 49.9 & $51 \cdot 2$ & $52 \cdot 1$ & 53.7 & $57 \cdot 0$ & 61.4 & $64 \cdot 3$ & $66 \cdot 6$ & $70 \cdot 7$ \\
\hline 9 & $51 \cdot 3$ & $52 \cdot 8$ & $53 \cdot 8$ & 55.5 & $59 \cdot 2$ & 63.9 & $67 \cdot 0$ & 69.5 & $73 \cdot 8$ \\
\hline 10 & $52 \cdot 4$ & $53 \cdot 8$ & 54.9 & $56 \cdot 6$ & $60 \cdot 3$ & $65 \cdot 0$ & $68 \cdot 1$ & $70 \cdot 5$ & 74.7 \\
\hline
\end{tabular}

International Obesity Task Force cut-offs are now widely accepted. Using this reference, the frequencies of obesity and overweight (including obesity) in the same sample of the present study were 5.5 and $22.1 \%$ respectively (de Assis et al. 2005). For WC, some studies have derived WC cutoffs on the basis of the relationship with metabolic risk factors (Freedman et al. 1999; Maffeis et al. 2001; Moreno et al. 2002; Katzmarzyk et al. 2004). The optimal threshold differed markedly between these studies, depending on the number and type of metabolic risk factors and probably due to ethnic and environmental differences between populations. Others have developed thresholds on the basis of the correlation of WC
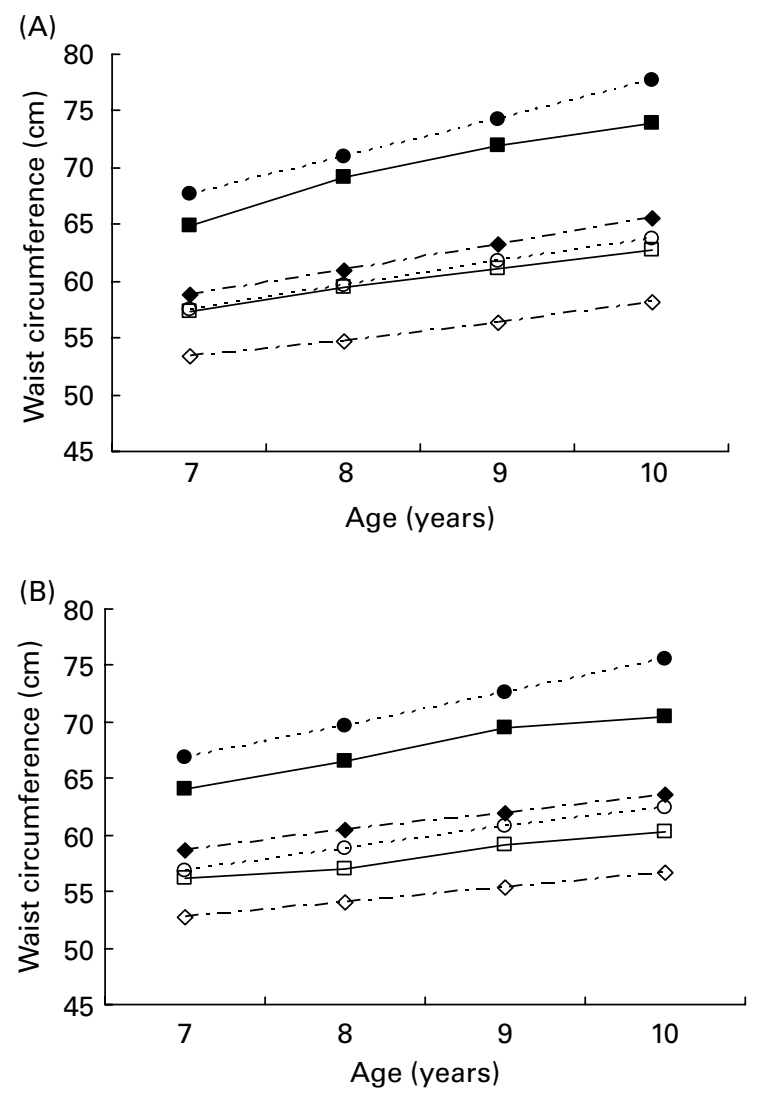

Fig. 1. Comparisons of the 50th and 90th percentiles for waist circumference obtained from the UK, the USA and Brazil (Florianopolis city) for boys (A)

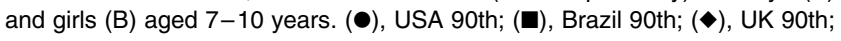
$(\bigcirc)$, USA 50th; $(\square)$, Brazil 50th; $(\diamond)$, UK 50th. with high trunk fat mass (Taylor et al. 2000), or based on the distribution of WC data from reference populations (McCarthy et al. 2003; Fredriks et al. 2005). In the absence of Brazilian WC reference data, we chose the criterion proposed by McCarthy et al. (2003), based on British reference data, to compare frequencies of nutritional status categories as defined by BMI and WC.

The results of the present study showed that, using BMI or WC, there were higher frequencies of Brazilian children with total and central adiposity compared with the corresponding age and sex data from the British references, except for BMI-defined overweight prevalence in 10-yearold girls. According to the cut-off points corresponding to the 91st and 98th centiles to define central adiposity based on WC (McCarthy et al. 2001) and overall adiposity based on BMI (Cole et al. 1995), we found higher frequencies of children with centrally distributed adiposity than total overweight and obesity. The prevalence rates recorded in the present study agree with those reported in British adolescents aged 11-16 years (McCarthy et al. 2003), using the same British references for WC and BMI, regardless of the different age ranges between the two studies. In the British study centrally distributed adiposity affected a higher percentage of youth than total obesity (McCarthy et al. 2003). In Australian children aged 7-8 years, the WC identified a greater number of boys over the cut-off point (as defined by the 91st percentile) compared with the BMI cut-off points (as defined by International Obesity Task Force references). However, more girls were identified by BMI cut-offs as overweight or obese compared with the WC cut-off points (Garnett et al. 2005).

In the present study, we analysed indirect associations among measures of adiposity and physical growth. The correlation between WC and height suggests that the increase in WC in childhood is due in part to linear growth, as stated by others (McCarthy \& Ashwell, 2006). In fact, children identified by the WC cut-off as at risk of abdominal adiposity but not by BMI cut-off were $7 \mathrm{~cm}$ taller, suggesting that the magnitude in the WC can be in part explained by the difference in height. Although children classified as at risk of abdominal adiposity according to the WC cut-offs (WC-only group) presented a significantly higher WHtR compared with children classified only by the BMI cut-offs (BMI-only group), the clinical significance of this increase $(P<0 \cdot 01)$ may be irrelevant. It is important, however, to examine the WHtR, as this index takes height into account. 
Table 3. Frequencies (\%) of overweight and obese 7- to 10-year-old boys and girls defined according to body mass index (1990 British reference data; Cole et al. 1995) and frequencies (\%) of excess and at-risk abdominal adiposity defined according to waist circumference (WC) (McCarthy et al. 2001)

\begin{tabular}{|c|c|c|c|c|c|c|c|c|}
\hline \multirow[b]{3}{*}{ Age (years) } & \multicolumn{4}{|c|}{ BMI } & \multicolumn{4}{|c|}{ WC } \\
\hline & \multicolumn{2}{|c|}{ Obese } & \multicolumn{2}{|c|}{ Overweight } & \multicolumn{2}{|c|}{ Excess } & \multicolumn{2}{|c|}{ At risk } \\
\hline & Boys & Girls & Boys & Girls & Boys & Girls & Boys & Girls \\
\hline 7 & 8.3 & 5.6 & 10.4 & $9 \cdot 6$ & 11.3 & $7 \cdot 7$ & 14.5 & $12 \cdot 1$ \\
\hline 8 & $10 \cdot 4$ & 6.5 & $12 \cdot 2$ & $12 \cdot 2$ & $18 \cdot 2^{*}$ & $10 \cdot 7$ & 13.5 & $10 \cdot 2$ \\
\hline 9 & 8.3 & $6 \cdot 4$ & $11 \cdot 1$ & $9 \cdot 7$ & $13 \cdot 7^{\star}$ & $12 \cdot 3$ & 13.0 & 11.3 \\
\hline 10 & $6 \cdot 2$ & 3.8 & $13 \cdot 5^{\star}$ & 5.9 & 9.8 & $9 \cdot 2$ & 13.2 & 14.5 \\
\hline Total & 8.3 & 5.6 & 11.8 & $9 \cdot 4$ & 13.4 & $10 \cdot 1$ & 13.5 & 11.9 \\
\hline
\end{tabular}

${ }^{*}$ Frequency was significantly different from that of the girls $(P<0.01)$.

The WHtR has recently been proposed as an index to assess central adiposity in children and adolescents, based on evidence that it is a better predictor of CVD risk factors than the BMI (Savva et al. 2000; Kahn et al. 2005; McCarthy \& Ashwell, 2006). Although WC measurement cannot differentiate between visceral and subcutaneous adiposity stores, it has been shown that WC is a good predictor of visceral fat, linked to increased risk of metabolic diseases in children and adolescents (Hirschler et al. 2005; Lee et al. 2006).

Values of WC at the 90th percentile in Florianopolis children were higher than those from British data (1977-87) (McCarthy et al. 2001) but lower than those found in European-American children (Fernández et al. 2004), in the same age range. Indeed, the 75 th percentile in boys and girls of Florianopolis approached or exceeded the 95th percentiles in British children (McCarthy et al. 2001). These comparisons should be interpreted considering several important differences between the studies, such as the site of waist measurement, the date of data collection, the method of derivation of the percentile values and the genetic, ethnic and socio-economic characteristics of the populations. Data from the UK and in the present study were measured midway between the tenth rib and the iliac crest and the derivation of percentile values were developed using the LMS method. The USA study used the site just above the uppermost lateral border of the right ilium for measurement of the WC and percentile

Table 4. Ancillary anthropometric variables among subgroups of children with discordant status (above cut-offs) defined according to the body mass index and waist circumference (WC) cut-offs

(Mean values and standard deviations)

\begin{tabular}{|c|c|c|c|c|c|}
\hline & \multicolumn{5}{|c|}{ Subgroups of children above cut-offs according to } \\
\hline & \multicolumn{2}{|c|}{ WC only* (n 252) } & \multicolumn{2}{|c|}{ BMI only† ( $n$ 52) } & \multirow[b]{2}{*}{$P$} \\
\hline & Mean & SD & Mean & SD & \\
\hline Height (cm) & $138 \cdot 9$ & $8 \cdot 4$ & 131.5 & $7 \cdot 6$ & 0.000 \\
\hline WHtR & 0.47 & 0.03 & 0.46 & 0.03 & 0.01 \\
\hline STR & 0.67 & 0.33 & 0.61 & $0 \cdot 18$ & 0.3 \\
\hline
\end{tabular}

WHtR, waist:height ratio; STR, subscapular:triceps skinfold ratio.

${ }^{*}$ Children classified as at risk of abdominal adiposity according to the WC cut-off, but not as overweight and obese according to the BMI cut-off.

†Children classified as overweight and obese according to the BMI cut-off, but not as at risk of abdominal adiposity by the WC cut-off. regression to model centiles. These issues have been discussed elsewhere (McCarthy et al. 2001; Eisenmann, 2005).

These data add to the existing WC percentile distributions developed for children and youth in Italy (Zannolli \& Morgese, 1996), Spain (Moreno et al. 1999), the UK (McCarthy et al. 2001), Cyprus (Savva et al. 2001), Australia (Eisenmann, 2005) and the USA (Fernández et al. 2004). There are important differences in mean values of WC for age between countries, with the highest values for the USA and Cyprus and the lowest for the UK, with intermediate values for Australia, Italy, and Spain. Unmeasured factors such as socio-economic, dietary and physical activity patterns, and ethnic characteristics might explain some of the variation in the WC values between studies. In a representative sample of US children and adolescents (NHANES III), the distribution of WC differed according to ethnic origins in boys and girls (Fernández et al. 2004). An inverse association among high cardiorespiratory fitness and central obesity (defined by the subscapular skinfold and sum of trunk skinfolds), BMI and percentage body fat was showed in Greek children aged 6-13 years (Nassis et al. 2005).

In conclusion, WC percentile distributions of Florianopolis schoolchildren aged 7-10 years showed higher values than British reference data and lower values than American data. Compared with British children, the schoolchildren from Florianopolis were heavier and had a more marked central distribution of body fat. Using British references for WC and BMI, centrally distributed adiposity was more prevalent than total overweight and obesity.

Taking these data as baseline, regular and frequent monitoring of childhood WC values would be advisable. Even if the gold standard to define centrally distributed adiposity prevalence remains uncertain, valid within-population comparisons of relative changes can be made against the same standard over time. More research is required to identify optimal WC cut-offs related to elevated risk factor levels in children and to establish international reference data for WC.

\section{Acknowledgements}

The present study was supported by the Fundação de Amparo à Pesquisa de Santa Catarina (FAPESC), the Secretaria da Saúde - Prefeitura Municipal de Florianopolis and the 
Universidade Federal de Santa Catarina (UFSC). We gratefully thank the staff of the schools as well as the children and their parents for their participation in the study.

\section{References}

Brambilla P, Bedogni G, Moreno LA, Goran MI, Gutin B, Fox KR, Peters DM, Barbeau P, De Simone M \& Pietrobelli A (2006) Crossvalidation of anthropometry against magnetic resonance imaging for the assessment of visceral and subcutaneous adipose tissue in children. Int J Obes 30, 23-30.

Cole TJ (1990) The LMS method for constructing normalized growth standards. Eur J Clin Nutr 44, 45-60.

Cole TJ, Bellizi MC, Flegal KM \& Dietz WH (2000) Establishing a standard definition for child overweight and obesity worldwide: international survey. BMJ 320, 1240-1243.

Cole TJ, Freeman JV \& Preece MA (1995) Body mass index reference curves for the UK, 1990. Arch Dis Child 73, 25-29.

de Assis MA, Rolland-Cachera MF, Grosseman S, de Vasconcelos FA, Luna ME, Calvo MC, Barros MV, Pires MM \& Bellisle F (2005) Obesity, overweight and thinness in schoolchildren of the city of Florianopolis, Southern Brazil. Eur J Clin Nutr 59, 1015-1021.

Eisenmann JC (2005) Waist circumference percentiles for 7- to 15year-old Australian children. Acta Paediatr 94, 1182-1185.

Fernández JR, Redden DT, Pietrobelli A \& Allison DB (2004) Waist circumference percentiles in nationally representative samples of African-American, European-American, and Mexican-American children and adolescents. J Pediatr 145, 439-444.

Fredriks AM, van Buuren S, Fekkes M, Verloove-Vanhorick SP \& Wit JM (2005) Are age references for waist circumference, hip circumference and waist-hip ratio in Dutch children useful in clinical practice? Eur J Pediatr 164, 216-222.

Freedman DS, Serdula MK, Srinivasan SR, Gerald S \& Berenson GS (1999) Relation of circumferences and skinfold thicknesses to lipid and insulin concentrations in children and adolescents: the Bogalusa Heart Study. Am J Clin Nutr 69, 308-317.

Garnett SP, Cowell CT, Baur LA, Shrewsbury VA, Chan A, Crawford D, Salmon J, Campbell K \& Boulton TJ (2005) Increasing central adiposity: the Nepean longitudinal study of young people aged 7-8 to 12-13 y. Int J Obes 29, 1353-1360.

Hirschler V, Aranda C, Calcagno Mde L, Maccalini G \& Jadzinsky M (2005) Can waist circumference identify children with the metabolic syndrome? Arch Pediatr Adolesc Med 159, 740-744.

Kahn HS, Imperatore G \& Cheng YJ (2005) A population-based comparison of BMI percentiles and waist-to-height ratio for identifying cardiovascular risk in youth. J Pediatr 146, 482-488.

Katzmarzyk PT, Srinivasan SR, Chen W, Malina RM, Bouchard C \& Berenson GS (2004) Body mass index, waist circumference, and clustering of cardiovascular disease risk factors in a biracial sample of children and adolescents. Pediatrics 114, e198-e205.

Lee S, Bacha F, Gungor N \& Arslanian AS (2006) Waist circumference is an independent predictor of insulin resistance in black and white youths. J Pediatr 148, 188-194.
Lohman TG, Roche AF \& Martorell R (1988) Anthropometric Standardization Reference Manual. Champaign, IL: Human Kinetics.

McCarthy HD \& Ashwell M (2006) A study of central fatness using waist-to-height ratios in UK children and adolescents over two decades supports the simple message - 'keep your waist circumference to less than half your height'. Int $J$ Obes 30, 988-992.

McCarthy HD, Ellis SM \& Cole TJ (2003) Central overweight and obesity in British youth aged 11-16 years: cross sectional surveys of waist circumference. BMJ 326, 624-626.

McCarthy HD, Jarrett KV \& Crawley HF (2001) The development of waist circumference percentiles in British children aged 5.0$16 \cdot 9$ y. Eur J Clin Nutr 55, 902-907.

McCarthy HD, Jarrett KV, Emmett PM \& Rogers I (2005) Trends in waist circumferences in young British children: a comparative study. Int J Obes 29, 157-162.

Maffeis C, Pietrobelli A, Grezzani A, Provera S \& Tato L (2001) Waist circumference and cardiovascular risk factors in prepubertal children. Obes Res 9, 179-187.

Moreno LA, Fleta J, Mur L, Rodriquez G, Sarria A \& Bueno M (1999) Waist circumference values in Spanish children - gender related differences. Eur J Clin Nutr 53, 429-433.

Moreno LA, Pineda I, Rodriguez G, Fleta J, Sarria A \& Bueno M (2002) Waist circumference for the screening of the metabolic syndrome in children. Acta Paediatr 91, 1307-1312.

Moreno LA, Sarria A, Fleta J, Marcos A \& Bueno M (2005) Secular trends in waist circumference in Spanish adolescents, 1995 to 2000-02. Arch Dis Child 90, 818-819.

Nassis GP, Psarra G \& Sidossis LS (2005) Central and total adiposity are lower in overweight and obese children with high cardiorespiratory fitness. Eur J Clin Nutr 59, 137-141.

Reilly JJ, Dorosty AR \& Emmett PMAvon Longitudinal Study of Pregnancy and Childhood Study Team (2000) Identification of the obese child: adequacy of the body mass index for clinical practice and epidemiology. Int $J$ Obes Relat Metab Disord 24, $1623-1627$.

Savva SC, Kourides Y, Tornaritis M, Savva ME, Tafouna P \& Kafatos A (2001) Reference growth curves for Cypriot children 6 to 17 years of age. Obes Res 9, 754-762.

Savva SC, Tornaritis M, Savva ME, Kourides Y, Panagi A, Silikiotou N, Georgiou C \& Kafatos A (2000) Waist circumference and waist-to-height ratio are better predictors of cardiovascular disease risk factors in children than body mass index. Int $J$ Obes Relat Metab Disord 24, 1453-1458.

Taylor RW, Jones IE, Williams SM \& Goulding A (2000) Evaluation of waist circumference, waist-to-hip ratio, and the conicity index as screening tools for high trunk fat mass, as measured by dual-energy X-ray absorptiometry, in children aged 3-19y. Am J Clin Nutr 72, 490-495.

Wang Y, Monteiro C \& Popkin BM (2002) Trends of obesity and underweight in older children and adolescents in the United States, Brazil, China, and Russia. Am J Clin Nutr 75, 971-977.

Zannolli R \& Morgese G (1996) Waist percentiles: a simple test for atherogenic disease? Acta Paediatr 85, 1368-1369. 